\title{
EFEKTIFITAS MODEL ACTIVE DALAM PEMBELAJARAN PRAKTEK TAHAP PROFESI NERS DI STIKES SUKABUMI
}

\author{
Irawan Danismaya \\ Sekolah Tinggi Ilmu Kesehatan Sukabumi \\ E-mail : idanismaya@yahoo.co.id
}

\begin{abstract}
ABSTRAK
Pendidikan Ners Indonesia memiliki 2 tahap program pembelajaran yaitu Tahap akademik dan Tahap Profesi.Model pembelajaran praktek Tahap Profesi di perguruan tinggi Keperawatan sangat bervariasi tergantung pada profil lulusan yang diharapkannya. STIKES Sukabumi telah menerapkan model ACTIVE yang dievaluasi keefektifannya secara periodik. Variabel penelitian yaitu tingkat keterampilan menerapkan Proses Keperawatan, Proses Manajemen dan tingkat rasa aman mahasiswa. 99 mahasiswa yang tercatat pada tahun akademik 2016/2017 ditetapkan sebagai responden menggunakan teknik total sampling. Pengumpulan data menggunakan 3 jenis kuisioner berskala Likert. Analisis data dilakukan untuk menemukan nilai tengah dan distribusi frekuensinya. Tahap Perumusan Diagnosis Keperawatan memiliki nilai tertinggi yaitu $81,82 \%$ dan rata-rata tertinggi pada tahap Implementasi Keperawatan yaitu 3,16. Tahap Actuating memiliki nilai tertinggi yaitu $40,40 \%$ dan rata-rata tertinggi pada tahap Communicatingyaitu 3,08.Tingkat rasa aman mahasiswa sebagian besar termasuk dalam kategori cemas ringan dengan nilai $83,84 \%$. Kesimpulan penelitian yaitu tingkat kompetensi mahasiswa dalam menerapkan Proses Keperawatan berada pada level New Beginner menuju Proficient.Tingkat keterampilan mahasiswa dalam menerapkan Proses Manajemen berada pada level New Beginner sampai Competent. Tingkat rasa aman saat menjalankan pembelajaran praktek sebagian besar pada kategori cemas ringan. Saran ditujukan kepada pihak pengelola lahan praktek, program studi dan Peneliti selanjutnya.
\end{abstract}

Kata Kunci : Proses Keperawatan ; Proses Manajemen ; Rasa Aman; Tingkat kompetensi

\section{ACTIVE MODEL EFFECTIVITY IN PRACTICE LEARNING OF NURSING EDUCATION PROFESSION PHASE AT STIKES SUKABUMI}

\author{
Irawan Danismaya \\ Sekolah Tinggi Ilmu Kesehatan Sukabumi \\ E-mail : idanismaya@yahoo.co.id
}

\begin{abstract}
Indonesian Nursing Education has two learning programs which is Academic Phase and Profession Phase. Practice learning model of Profession Phase in nursing college are various and depends on its targeted alumni profile. STIKES Sukabumi have implemented ACTIVE model which effectivity have been evaluated periodically. Research variables are the implementation skill level of Nursing Process, Management Process, and Student's Sense of Security. 99 students those are registered in academic year 2016/2017 are chosen as respondents in a total sampling technique data gathering. The data gathering uses 3 kinds of Likert scaled questionnaire. Data analysis is purposed to find the median and frequency distribution. Nursing Diagnosis Formulation phase has the highest value that is $81,82 \%$ and the highest average value in Nursing Implementation phase is 3,16. The Actuating phase has the highest value that is 40,40\% dan the highest average value in Communicating phase is 3,08. The majority of student's Sense of Security belongs to slight anxienty category with value $83,84 \%$. The conclusion of this research is that the student's competency level in implementing Nursing Process is categorized in New Beginner to Proficient level. The student's skill level in implementing Management Process is categorized in New Beginner to Competent level. The Sense of Security while in practice learning progress is categorized in slight anxienty category in majority. Advise is addressed to practice field administrator, study program, and future researchers
\end{abstract}

Key words : Competency Level ; Managemen Process ; Nursing Process ; Sense of Security 


\section{Pendahuluan}

Pendidikan tinggi keperawatan Indonesia merujuk pada Undang-undang nomor 38 tahun 2014 dibedakan menjadi 2 yaitu pendidikan Vokasi dan Pendidikan Profesi. Pendidikan Ners merupakan jenjang Strata 1 yang bertujuan menghasilkan perawat profesional.Program pendidikan Ners memiliki dua tahap pembelajaran yaitu Tahap Akademik danTahap Profesisebagai satu kesatuan tak terpisahkan.Mahasiswa keperawatan secara bertahap diarahkan untuk memahami teori dan konsep di kelas /laboratorium lalu menerapkannya di lahan praktek. Tujuan akhir dari program Pendidikan Ners mengutip dari AIPNI (2015) yaitu berupaya mencapai profile lulusan sebagai Manager and Leader, Coomunicator, Educator and Helath Promotor, Researcher dan Care Provider.

Model pembelajaran yang teruji harus senantiasa diterapkan untuk memastikan bahwa tujuan setiap tahap pembelajaran dapat dicapai.Diskusi dengan para pengelola intitusi pendidikan Ners di Jawa Barat ditemukan banyak perbedaan dalam model pembelajaran praktek tahap profesi.Meskipun Kurikulum 2015 dari AIPNI sudah dijadikan pedoman oleh para anggotanya. Tantangan lainnya adalah bagaimana konsep pembelajaran terintegrasi dapat diaplikasikan.

Seringkali mahasiswa belajar menerapkan tahap Proses Keperawatan (PK) dalam situasi lahan praktek sedang bermasalah secara manajemen.Atau sebaliknya ketika mahasiswa belajar menerapkan tahap Proses Manajemen Keperawatan (MK), tetapi asuhan keperawatan kepada pasien secara individual menjadi terabaikan.Mahasiswa harus diyakinkan mampu memahami bahwa PK dan MK tidak terpisahkan dan harus dilakukan secara bersamaan. Prosesbelajar Tahap Profesi juga sering membebani mahasiswa dengan kegiatan menulis dan mempelajari konsep. Padahal idealnya harusmenggiring mahasiswa untukbelajar mengaplikasikan konsep/teori yang sudah dipelajari di Tahap Akademik. Ini akan menjadi persoalan jika lulusan program Pendidikan Ners hanya memiliki kemampuan kognitif yang tinggi namun lemah dalam menerapkan sebuah konsep. Persatuan Perawat Nasional Indonesia (PPNI) dengan jelas menegaskan bahwa Tahap Akademik ditujukan pada upaya penguasaan dan pengembangan ilmu keperawatan, sedangkan Tahap Profesi dilaksanakan agar mahasiswa mampu bekerja sesuai standar praktek profesi Keperawatan. (www.inna-ppni.or.id, diakses $\underline{\text { Juli 2016). }}$ 
STIKES Sukabumi menerapkan pola dasar Preseptorshipdalam pembelajaran praktek Tahap Profesi. Mahasiswa belajar langsung dari para Perawat bagaimana cara memperlakukan pasien, melakukan prosedur dan berperilaku etis selama melaksanakan asuhan keperawatan. Praktek klinik hanya dilaksanakan di lahan praktek yang konsisten menerapkan PK pada setiap pasien yang didukung manajemen unit secara baik.Mahasiswa diarahkan untuk menerapkan langkah-langkah Tahap MK dan Tahap PK untuk mencapai 5 profil lulusan Pendidikan Ners.

Tahap Profesi Pendidikan Ners di STIKES Sukabumi memiliki beban studi 36 SKS yang terbagi 2 semester dengan titik berat pada belajar menerapkan teori asuhan keperawatan dan tahap proses manajemen. Ada 3 aspek yang dinilai terkait penerapan Proses Keperawatan yaitu penampilan klinik, verbal respon dan dokumentasi.Sedangkankemampuan menerapkan Proses Manajemen dinilai dari keterampilan Planning Process, Leadership Skill dan dokumentasi.Kerangka model pembelajaran terintegrasi ini dirumuskan dalam langkahlangkah kegiatan praktek klinik yang disebut model ACTIVE.

Studi pendahuluan terhadap pengetahuan mahasiswa Tahap Profesi Tahun Akademik 2015/2016 tentang teori 5 Tahap PK lebih dari 80 \% termasuk kategori baik.Tetapi tingkat keterampilan menerapkan tahapan proses teridentifikasi dalam kategori cukup sampai buruk. 8 orang mengaku bingung saat harus melakukan pengkajian dalam situasi sibuk karena jumlah pasien yang banyak.Mereka juga merasa kesulitan dalam memilih aspek-aspek fokus yang harus dikaji.Keterampilanmencatat secara berkesinambungan kegiatan asuhan per-24 jam pun sangat lemah.Kondisiini relevan dengan hasil penelitian Elta (2016) bahwa terdapat hubungan antara nilai Indek Prestasi Kumulatif Tahap Akademik dengan kemampuan menerapkan Proses Keperawatan di Tahap Profesi.

Terkait pembelajaran dalam menerapkan proses $\mathrm{MK}, 12$ orang menyatakan tidak tahu bagaimana cara memulai proses manajemen di satu tempat yang berkali-kali menjadi lahan praktek. Mereka juga mengaku malu dan merasa tidak percaya diri pada mereka saat harus berkomunikasi dengan para seniornya.Metode pembelajaran praktek manajemen di Perguruan Tinggi (PT) Keperawatan Jawa Barat teridentifikasi terbagi dalam 2 bentuk pendekatan.Pengelola akademik 7 PT menyatakan menerapkan proses belajar praktek manajemen secara komprehensif berbasis visi institusi pelayanan kesehatan, sedangkan 3 PT 
lainnya menerapkan model belajar praktek manajemen berbasis masalah, termasuk di STIKES Sukabumi. Keraguan terhadap efektifitas model seringkali menjadi topik diskusi diantara pengelola program studi Keperawatan di STIKES Sukabumi. Evaluasi terhadap target program selalu dilakukan secara berkala di setiap akhir program pendidikan.

Berdasarkan dari penerapan model pembelajaran ACTIVE yang telah dilaksanakan pada tahap Profesi Program Pendidikan Ners di STIKES Sukabumi, maka disusun sebuah rumusan masalah yaitu ; “Bagaimana efektifitas model ACTIVE dalam Pembelajaran Praktek Tahap Profesi Pendidikan Ners Di STIKES Sukabumi ? “

\section{Tinjauan Teoritis}

Pendidikan Ners Indonesia terdiri dari 2 tahap program pembelajaran yaitu Tahap Akademik dan Tahap Profesi. Pendidikan tahap akademik diarahkan pada penguasaan dan pengembangan cabang Ilmu Pengetahuan dan Teknologi (Pasal 15 UU no 12 Tahun 2012). Tahap profesi disebutkan sebagai program pendidikan setelah program sarjana yang ditujukan untuk mempersiapkan mahasiswa agar mampu bekerja dalam sebuah pekerjaan yang memerlukan persyaratan keahlian khusus. Lulusannya disebutkan Nursalam (2011) harus mampu memberikan perawatan yang sesuai dengan kebutuhan objektif klien, dan melakukan supervisi praktik keperawatan yang dilakukan oleh perawat profesional pemula. Program Pendidikan Ners di STIKES Sukabumi didasarkan pada standar kurikulum pendidikan tinggi dari Kementrian Riset \& Pendidikan Tinggi Indonesia dan Asosiasi Penyelenggara Pendidikan Ners Indonesia (AIPNI)

Nursing Process atau Proses Keperawatan (PK) adalah pola berfikir ilmiah yang harus dilakukan oleh setiap perawat dan hanya akan efektif jika diterapkan dalam sebuh lingkungan kerja yang menerapkan proses Managemen Keperawatan (MK) secara baik. PK dan MK adalah proses yang searah, tidak terpisahkan dan bertujuan sama yaitu tercapainya kepuasan pasien. Pembelajaran praktek tahap profesi di STIKES Sukabumi memfasilitasi penerapan PK dan MKsecara terintegrasi dan disebut model ACTIVE (Danismaya, 2014).Kegiatan pembelajaran dalam model "ACTIVE" merupakan serangkaian aktivitas belajar yang sistematis, bertahap dan berkesinambungan yang terdiri dari : 
1. Asessment (A) : Kegiatan yang bertujuan untuk mengidentifikasi masalah/gap yang sedang terjadi di lahan praktek area kajian dengan cara melibatkan diri secara langsung agar dapat merasakan masalah tersebut.

2. Communicating(C): Mahasiswa mengkomunikasikan hasil kajian situasi yang telah dilakukannya kepada stake holder di lahan praktek.

3. Team of Care Celivery : Mahasiswa melibatkan diri sebagai anggota tim kerja (Team Work) untuk melaksanakan Planning berbasis evidance base practice.

4. Individual case management : mahasiswa bertanggung jawab mengelola satu kasus individu/keluarga/kelompok/masyarakat dengan pendekatan total care.

5. Verbal response : Mahasiswaharus mampu mempertanggungjawabkan kasus yang telah dikelolanya.

6. Evaluation :Kegiatan bersama antara mahasiswa dengan pihak lahan praktek untuk mengevaluasi hasil yang diperoleh.

\section{Metode Penelitian}

Pembelajaran Praktek Tahap Profesi merupakan kegiatan yang dilakukan oleh mahasiswa setelah berhasil melalui serangkaian pembelajaran di kelas dan laboratorium pada tahap akademik. 3 variabel yang diukur yaitu : keterampilan menerapkan Proses Keperawatan, menerapkan Proses Manajemen dan rasa aman selama menjalankan praktek.

Kompetensi yang diukur merujuk pada kompetensi level Pemula (Advanced beginner) yang dicirikan oleh tercapainya pola perilaku berulang yang terdokumentasi dengan menggunakan standar pengajaran dan rencana perawatan pasien, serta merujuk pada kebutuhan pasien dan keluarganya. Rasa aman adalah pengalaman psikologis yang dirasakan selama menjalankan belajar di lahan praktek.Penelitian dilakukan sejak Pebruari sampai dengan Juli 2017 di Kampus STIKES Sukabumi. Populasi adalah seluruh mahasiswa pada tahun akademik 2016/2017 yang tercatat aktif. Digunakan teknik Total Sampling sehingga 99 orang mahasiswa menjadi sampelnya.

Pengumpulan data dilakukan setelah proses yudisium dilakukan oleh pengelola program studi. Menggunakan 3 buah instrumenyang berisi pernyataan yang meminta jawaban kepada responden dalam skala Likert dari 1 sampai 5. Rasa aman diukur menggunakan intrumen dari HARS. Analisa data dilakukan untuk menemukan distribusi frekuensi dan nilai tengahnya. 


\section{Hasil penelitian}

Responden 99 orang terbagi dalam 2 kelompok praktikan terdiri dari $58.59 \%$ pria dan 41.41 $\%$ wanita. $19,9 \%$ berlatar belakang program transfer dari pegawai dan $80.81 \%$ merupakan program reguler. $100 \%$ responden mengikuti proses Pra Profesi. Tabel 1 sampai 12 menggambarkan nilai distribusi frekuensi dan nilai tengah dari seluruh variabel penelitian.

Tabel 1Distribusi Frekuensi Keterampilan Pengkajian Keperawatan

\begin{tabular}{cc}
\hline Level & $\%$ \\
\hline Novice & 5,05 \\
Advance Beginner & 15,15 \\
Competent & 78,79 \\
Proficient & 1,01 \\
Expert & 0,0 \\
\hline
\end{tabular}

Tabel 3Distribusi Frekuensi Keterampilan Perencanaan Keperawatan

\begin{tabular}{cc}
\hline Level & $\%$ \\
\hline Novice & 26,26 \\
Advance Beginner & 29,29 \\
Competent & 44,44 \\
Proficient & 0,0 \\
Expert & 0,0 \\
\hline
\end{tabular}

Tabel 5Distribusi Frekuensi Keterampilan Evaluasi Keperawatan

\begin{tabular}{cc}
\hline Level & $\%$ \\
\hline Novice & 6,06 \\
Advance Beginner & 18,18 \\
Competent & 73,74 \\
Proficient & 2,02 \\
Expert & 0,0 \\
\hline
\end{tabular}

Tabel 7 Distribusi Frekuensi Keterampilan Planning Phase

\begin{tabular}{cc}
\hline Level & $\%$ \\
\hline Novice & 3,03 \\
Advance Beginner & 56,57 \\
Competent & 36,36 \\
Proficient & 4,04 \\
Expert & 0,0 \\
\hline
\end{tabular}

Tabel 9 Distribusi Frekuensi Keterampilan Actuating Phase
Tabel 2 Distribusi Frekuensi Keterampilan Diagnosis Keperawatan

\begin{tabular}{cc}
\hline Level & $\%$ \\
\hline Novice & 6,06 \\
Advance Beginner & 10,10 \\
Competent & 81,82 \\
Proficient & 2,02 \\
Expert & 0,0 \\
\hline
\end{tabular}

Tabel 4Distribusi Frekuensi Keterampilan Implementasi Keperawatan

\begin{tabular}{cc}
\hline Level & \% \\
\hline Novice & 2,02 \\
Advance Beginner & 6,06 \\
Competent & 65,66 \\
Proficient & 26,26 \\
Expert & 0,0 \\
\hline
\end{tabular}

Tabel 6Rerata Skor Pertahap Proses Keperawatan

\begin{tabular}{cc}
\hline Tahap & Rerata \\
\hline Pengkajian & 2.76 \\
Diagnosis Kep & 2,79 \\
Perencanaan & 2,18 \\
Implementasi & 3,16 \\
Evaluasi & 2,72 \\
\hline
\end{tabular}

Tabel 8 Distribusi Frekuensi Keterampilan Communicating Phase

\begin{tabular}{cc}
\hline Level & $\%$ \\
\hline Novice & 0,0 \\
Advance Beginner & 30,30 \\
Competent & 36,36 \\
Proficient & 28,28 \\
Expert & 5,05 \\
\hline & \\
\hline Novice & 0,0 \\
Advance Beginner & 29,29 \\
Competent & 40,40 \\
Proficient & 27,27 \\
Expert & 3,03 \\
\hline
\end{tabular}

Level \%


Tabel 10 Distribusi Frekuensi Keterampilan Evaluating Phase

\section{Level}

$\%$

Tabel 11 Rerata Skor Pertahap Proses Manajemen

\begin{tabular}{cc}
\hline Tahap & Rerata \\
\hline Planning Phase & 2,41 \\
Communicating Phase & 3,08 \\
Actuating Phase & 3,04 \\
Evaluating Phase & 2,40 \\
\hline
\end{tabular}

\begin{tabular}{cc}
\hline Novice & 2,02 \\
Advance Beginner & 57,57 \\
Competent & 38,38 \\
Proficient & 2,02 \\
Expert & 0.0 \\
\hline
\end{tabular}

Tabel 12 Distribusi Frekuensi Tingkat Rasa Aman Mahasiswa

\begin{tabular}{ccc}
\hline Tingkat Rasa Aman & Jumlah & $\%$ \\
\hline Cemas Berat & 2 & 2,02 \\
Cemas Sedang & 14 & 14,14 \\
Cemas Ringan & 83 & 83,84 \\
Total & 99 & 100 \\
\hline
\end{tabular}

\section{Pembahasan}

Hasil penelitian dikategorikan kompetensi sebagaimana yang dibuat oleh Jackson \& Hansten (2009)yaitu dari novice to expert. Keterampilan mahasiswa dalam melakukan pengkajian keperawatan terdistribusi paling besar pada level kompeten yaitu 78 orang mahasiswa. Artinya mampu mengumpulkan dan memilih data yang relevan dengan kondisi pasien tanpa dibantu. 1 orang tercatat mampu membantu dan mengajarkan kepada juniornya. Sedangkan keterampilan mahasiswa dalam merumuskan Diagnosis Keperawatan terdistribusi terbanyak dalam level kompeten yaitu 81 orang. Ini berarti bahwa mahasiswa yang bersangkutan mampu mengkategorikan, menganalisa dan merumuskan kesimpulan secara tepat tanpa dibantu. Hanya ada 2 orang yang masuk kategori proficient yaitu mampu mengajarkan kepada orang lain secara baik.

Kegiatan merumuskan rencana keperawatan dalam Perry \&Potter (2010) terdiri dari kegiatan memprioritaskan masalah, menyusun tujuan dan merumuskan rencana intervensinya. Terjadi peningkatan jumlah mahasiswa yang masuk dalam kategori Pemula/Novice yaitu 26 orang dibanding 2 tahap sebelumnya, artinya mahasiswa perlu didampingi dan bergantung kepada seniornya. Sedangkan saat memasuki tahap implementasi,juga terjadi peningkatan cukup besar pada kelompok Proficient yaitu 26 orang. Ini berarti secara skill prosedural mahasiswa mampu melaksanakan secara baik prosedur terkait dan mampu membantu rekannya saat melakukan prosedur.

Terdapat 73 orang mahasiswa termasuk dalam level Competent pada tahap kegiatan Evaluasi, meskipun 6 orang diantaranya berada pada level Novice yang berarti masih membutuhkan 
bimbingan/bergantung kepada orang lain. Lalu kompetensi dengan rata-rata tertinggi ada pada tahap implementasi yaitu 3,16 yang berarti masuk kategori competent menuju proficient. Paling rendah ada di tahap perencanaan yaitu 2,18 yang masuk kategori New beginner menuju competent. Jika merujuk pada kategori kompetensi dari Jackson \& Hansten (2009) maka kelompok mahasiswa dalam kategori Novice perlu mendapatkan perhatian dari pengelola Program Studi.

Pengukuran keterampilan mahasiswa dalam menerapkan MK berdasarkan 4 tahap kegiatan sesuai level kompetensi Pemula. Distribusi keterampilan tertinggi dalam fase Planning yaitu pada level advance beginner sebesar 56 orang. Planning proses merupakan kegiatan mahasiswa dalam mengidentifikasi problem manajemen yang sedang terjadi, dan lalu melakukan pengembangan data sehingga bisa dirumuskan menjadi masalah dan rencana solusinya. Sedangkan distribusi keterampilan mahasiswa dalam mengadvokasi dan mengkomunikasikan hasil perencanaan terbanyak ada pada level competent dan terlihat 5 orang masuk dalam kategori expert. Artinya mahasiswa mampu memahami dengan baik seluruh proses dan cara berkomunikasi serta bekerja dalam tim di sebuah organisasi.

Pada tahap pelaksanaan tugas semua mahasiswa tidak ada yang masuk dalam kategori perlu bimbingan atau bergantung kepada orang lain. Semua level terdistribusi hampir merata di level lainnya. 3 orang masuk kategori expert. Artinya sikap memotivasi diri sendiri dan motivasi kerja mampu diaplikasikan dengan baik oleh mahasiswa.Distribusi terbesar tahap evaluasi manajemen berada pada level advance beginner sesuai dengan level seharusnya kompetensi yang harus dimiliki mahasiswa. 2 orang mampu proficient namun tidak ada yang masuk kategori expert.Keterampilan pada tahap Planning dan Evaluasi terlihat pada level advance beginner menuju competent. Sedangkan keterampilan mahasiswa dalam tahap komunikasi dan implementasi masuk dalam kategori competent menuju level proficient.

Sebagian besar mahasiswa yaitu 83,84 \% menyatakanmengalami perasaan cemas ringan selama menjalankan kegiatan praktek. Kondisi yang sangat wajar mengingat kegiatan praktek adalah pengalaman baru bagi setiap mahasiswa yang bisa berpengaruh sebagai stressor psikologis(Kozier, dkk. 2010). Program Early Exposureyang dilaksanakan pada 2 semester Tahap Akademik, juga dibuat untuk membantu persiapan mental para mahasiswa (AIPNI, 2015). 


\section{Kesimpulan}

Tingkat kompetensi mahasiswa dalam menerapkan 5 tahap Proses Keperawatan berada pada level New Beginner menuju Proficient. Tingkat kompetensi mahasiswa dalam melaksanakan Tahap Proses Manajemenberada pada level New Beginner sampai Competent. Tingkat rasa aman mahasiswa saat menjalankan praktek klinik keperawatan sebagian besar berada pada level cemas ringan.

\section{Saran}

Saran ditujukan kepada lahan praktek agar tempat Penelitianmenciptakan mekanisme proses bimbingan yang dapat memfasilitasi mahasiswa untuk belajar kemandirian dan bekerja secara tim. Kepada Pengelola program studi perlu merancang program pembelajaran praktikum untuk belajar menerapkan langkah proses manajemen sejak dari Tahap Akademik pendidikan Ners. Lalu kepada Peneliti Selanjutnya agar teknik pengumpulan data perlu dikembangkan melalui metode observasi langsung. 


\section{Daftar Pustaka}

AIPNI.(2015). Kurikulum Pendidikan Ners Indonesia.

Alimul Aziz. (2009). KebutuhanDasar Manusia Aplikasi Konsepdan Proses Keperawatan.Jakarta. SalembaMedika.

ArikuntoSuharsimi. (2010). ProsedurPenelitianSuatuPendekatanPraktek. Jakarta. RinekaCipta.

Danismaya.(2014) .Model pembelajaran Praktek profesi Ners Stikes Sukabumi. Sukabumi : Stikes Kota Sukabumi.

Dinarti \&Aryani.(2009). Dokumentasi Keperawatan. Jakarta :Trans Info Media.

Elta, Annisa (2016) . Hubungan indeks Prestasi Kumulatif dengan kemampuan menerapkan Proses Keperawatan. Skripsi, Program Studi S1 Keperawatan, STIKES Sukabumi.

Hidayat, A. Aziz Alimul. (2009). Metode Penelitian Dan Teknik Analisa Data. Jakarta, Salemba Medika.

Hutapea \& Thoha. (2008).Kompetensi plus teori, desain, kasus \& penerapan untuk HR serta Organisasi yang dinamis.Jakarta, Gramedia Pustaka Utama.

Jackson \& Hansten. (2009).A Handbook for professional Practice Fourth Edition.Canada, Jones \& Bartlett publisher.

Kozier, dkk. (2010).BukuAjar fundamental keperawatankonsep, proses danpraktik. Jakarta, EGC.

Notoatmodjo, Soekidjo. (2010). Metodologi Penelitian Kesehatan. Jakarta, Rineka Cipta.

Perry, Potter. (2010). Fundamental Keperawatankonsep, proses danpraktik.Jakarta, EGC.

STIKES Sukabumi. (2016). Rekapitulasi Nilai angkatan 2007-2011.Sukabumi , STIKES Sukabumi.

Riwidikdo, Handoko. (2008). Statistik Kesehatan. Jogjakarta, Mitra Cendikia.

Undang - undang Nomor 12 tahun 2012 tentang Pendidikan Tinggi

www.inna-ppni.or.id, diakses Juli 2016. 